\title{
Dynamic Mechanical Properties of a Visible Light Curable Urethane Dimethacrylate Based Dental Resin
}

\author{
Jong Keun LEE, Ji Young KIM, and Bum Soon LIM*, \\ Department of Polymer Science and Engineering, Kumoh National Institute of Technology, \\ 188 Shinpyung Dong, Kumi, Kyungbuk 730-701, Korea \\ * Department of Dental Biomaterials, College of Dentistry and Intellectual Biointerface Engineering Research Center, \\ Seoul National University, Seoul 110-749, Korea
}

(Received June 16, 2003; Accepted August 29, 2003)

\begin{abstract}
The purpose of this study was to evaluate dynamic mechanical properties of urethane dimethacrylate (UDMA) and triethylene glycol dimethacrylate (TEGDMA) based dental resin. Dynamic mechanical properties of a visible light $(\lambda=400-500 \mathrm{~nm})$ curable UDMA/TEGDMA (70:30 in $\mathrm{wt} \%$ ) resin were investigated for specimens uncured, light-cured for $40 \mathrm{~s}$, and heated to $175^{\circ} \mathrm{C}$ subsequent to the irradiation for $40 \mathrm{~s}$. Differential scanning calorimetry (DSC) was also employed as a complementary technique. For the light-cured specimen, two abrupt drops in the log storage modulus $\left(E^{\prime}\right)$ and two peaks in the $\tan \delta v s$. temperature curve corresponding to the glass transition were observed. The storage modulus was slightly increased with increasing temperature between the two modulus drops. The DSC experiment showed that the light-cured specimen contains residual living groups trapped by the fast reaction, which lead to further reaction during post-cure heat treatment. This further thermal reaction is considered to be responsible for the modulus increase. After heating to $175^{\circ} \mathrm{C}$ above the DSC exothermic peak, most of the residual groups in the light-cured specimen were found to be reacted, showing a single decrease in modulus and a single peak in the $\tan \delta$ curve, and no exotherm in the DSC curve. With the aid of DSC data, the further thermal cure reaction with increasing temperature may occur within the glass transition region. The occurrence of the thermal reaction gives rise to the inaccuracy in determining the glass transition temperature $\left(T_{\mathrm{g}}\right)$.

KEY WORDS Dynamic Mechanical Analysis (DMA) / DSC / UDMA / Storage Modulus / Tan $\delta$ / Glass Transition /
\end{abstract}

It is well known that the dynamic mechanical analysis (DMA) is a very powerful technique for studying not only solid and viscoelastic liquids but also reactive materials undergoing changes in low molecular weight monomer to high molecular weight network. ${ }^{1}$ The DMA technique is to impart the controlled mechanical oscillation to a solid or viscoelastic liquid, and to measure in-phase and out-of-phase response of the specimen. One calculates the storage modulus $\left(E^{\prime}\right)$ from the in-phase and the loss modulus $\left(E^{\prime \prime}\right)$ from the out-of-phase response, which represent the energy stored and dissipated, respectively. Tan $\delta$, where $\delta$ is the phase angle between the stress and strain in the oscillatory experiment, is given by the ratio of energy dissipated to energy stored per cycle $\left(E^{\prime \prime} / E^{\prime}\right)$.

From the analysis of the dynamic mechanical parameters, useful information on material properties can be obtained such as bulk properties directly related to material performance and primary and secondary transitions not easily identified by other methods. Typically, the information concerning polymeric systems from DMA includes quantitative modulus, glass transitions, rate and extent of polymerization, quantification of gelation, degree of cross-linking, and changes in polymer chain mobility. Among the dynamic mechanical properties in dental polymeric materials, the $E^{\prime}$ as a parameter of materials stiffness and the glass transition temperature $\left(T_{\mathrm{g}}\right)$ as an index of cross-linking density or degree of conversion $(D C)$ are of great importance in terms of durability and performance in their clinical usage. $^{2}$

There have been several reports on examining the dynamic mechanical properties of dental polymeric materials. Clarke ${ }^{3}$ described the dynamic mechanical properties of bisphenol-A related resins. The dynamic mechanical properties of commercially available denture base resins that had been cured using a different energy sources (heat, microwave and visible light) were reported. ${ }^{4}$ DMA has been also employed to characterize the viscoelastic properties of commercially available dental lining materials. ${ }^{5-7}$ DMA may be used to characterize both the rate and extent of polymerization, as such processes are associated with time-dependent changes in the elastic modulus. Recently, the storage modulus of highly filled Bis-GMA (bisphenol-A glycerolate dimethacrylate) composites within PTFE tube has been monitored during light-cure and corrected into that of the composites without the tube. ${ }^{8}$

${ }^{\dagger}$ To whom correspondence should be addressed (TEL: +82-2-740-8692, FAX: +82-2-740-8694, E-mail: nowick@snu.ac.kr). 
<smiles>C=C(C)C(=O)OCCCOC(=O)NCCC(C)CC(C)(C)CNC(=O)OCCOC(=O)C(=C)C</smiles>

Urethane dimethacrylate (UDMA)<smiles>C=C(C)C(=O)OCCCOC(=O)C(C)C</smiles>

Triethylene glycol dimethacrylate (TEGDMA)<smiles>CC12CCC(C(=O)C1=O)C2(C)C</smiles>

di-Camphorquinone (CQ)<smiles>C=C(C)C(=O)OCC[N+](C)C</smiles>

2-(Dimethylamino)ethyl methacrylate (DMAEMA)<smiles>Cc1cc(C(C)(C)C)c(O)c(C(C)(C)C)c1</smiles>

Butylated hydroxytoluene (BHT)

Figure 1. Chemical structures of the reactants.

UDMA (urethane dimethacrylate) has been recently of interest as one of primary resins for dental resin composites. Compared with Bis-GMA, UDMA monomers have lower viscosity ${ }^{9}$ and the resin composites based on the monomers show enhanced mechanical properties. $^{9-12}$ There are many publications on characterizing the UDMA-based dental resin using $\mathrm{DSC}^{13}$ and FT$\mathrm{IR}^{14}$ techniques. However, little is known about dynamic mechanical properties of UDMA-based dental resins.

In this study, we intend to provide further understanding of a visible light curable UDMA-based resin by observing dynamic mechanical parameters of storage modulus $\left(E^{\prime}\right)$ and $\tan \delta\left(=E^{\prime \prime} / E^{\prime}\right)$ and try to interpret the viscoelastic behaviors which are important determinants of product performance for polymeric formulations designed for dentistry. Also, differential scanning calorimetry (DSC), which is recognized as a complementary technique to DMA, was used to confirm and explain the DMA data.

\section{EXPERIMENTAL}

Experimental resin was prepared from a $70: 30 \mathrm{wt} \%$ UDMA (urethane dimethacrylate, Esstech, USA) and TEGDMA (triethylene glycol dimethacylate, Esstech, USA), mechanically blended at room temperature for $30 \mathrm{~min}$. $0.7 \mathrm{wt} \%$ of CQ (di-camphorquinone, Polysciences, USA) as an initiator, $0.35 \mathrm{wt} \%$ of DMAEMA (2-(dimethylamino)ethyl methacrylate, Aldrich, USA) as an accelerator, and $0.05 \mathrm{wt} \%$ of BHT (butylated hydroxytoluene, Sigma, USA) as an inhibitor were subsequently added and mixed thoroughly by stirring for additional $120 \mathrm{~min}$ in dark environment. Chemical 
structures of the reactants were represented in Figure 1.

For the dynamic mechanical analysis (DMA 983, Dupont, USA), the uncured neat resin mixture was impregnated into a piece cut from a glass fiber mattress roll (TA Instrument, USA). The excess resin on the impregnated specimen was squeezed out between aluminum foils. The impregnated specimen was placed into the DMA heating chamber and scanned from -100 to $250^{\circ} \mathrm{C}$ at a fixed frequency of $1 \mathrm{~Hz}$ with a heating rate of $2^{\circ} \mathrm{C} \mathrm{min}^{-1}$. The liquid nitrogen used for cooling the system provides an inert atmosphere in this test. A light-cured specimen was prepared in a Teflon mold $[50 \mathrm{~mm}(\mathrm{~L}) \times 7 \mathrm{~mm}(\mathrm{~W}) \times 0.8 \mathrm{~mm}(\mathrm{~T})]$ where neat resin mixture was poured into the mold and then irradiated with a light curing unit (VIP; $\lambda=400-500 \mathrm{~nm}$, Bisco, USA) at an intensity of $500 \mathrm{~mW} \mathrm{~cm}^{-2}$. Irradiation on the specimen was made every $10 \mathrm{~mm}$ in a longitudinal direction for $40 \mathrm{~s}$ for both sides maintaining $1 \mathrm{~mm}$ gap between light guide and specimen surface. The light intensity and the irradiation time used in this experiment are based on the conditions in clinical applications of dental restorative composites. It should be noted that the spot diameter of emitting light of the curing unit is $11 \mathrm{~mm}$. Light energy density at the surface of the light guide was calibrated by a radiometer (Demetron model 100, USA) before irradiation.

Differential scanning calorimetry (DSC 910, DuPont, USA) was used mainly to confirm the results from DMA. A DSC thermogram was obtained for about $10 \mathrm{mg}$ of specimen, taken from the light-cured specimen at an intensity of $500 \mathrm{~mW} \mathrm{~cm}^{-2}$ for $40 \mathrm{~s}$ in the temperature range of -150 to $250^{\circ} \mathrm{C}$ at a heating rate of $10^{\circ} \mathrm{C} \mathrm{min}^{-1}$ under a dry nitrogen atmosphere.

Specimens irradiated for $40 \mathrm{~s}$ were heated to $175^{\circ} \mathrm{C}$ above their exothermic peak at a heating rate of $10^{\circ} \mathrm{C} \mathrm{min}^{-1}$. The post-cured specimens were also analyzed by means of DMA and DSC.

\section{RESULTS}

Figure 2 displays log relative storage modulus $\left(E_{\mathrm{R}}\right)$ data from DMA and heat flow from DSC $v s$. temperature for the uncured specimen. The relative storage modulus is originated from the composite nature (resin mixture + glass fiber mattress) of the specimen. As shown in the figure, $\log E_{\mathrm{R}}^{\prime}$ decreased abruptly between around $-70^{\circ} \mathrm{C}$ and $-40^{\circ} \mathrm{C}$, corresponding to the glass transition of the uncured resin. Between $-40^{\circ} \mathrm{C}$ and $100^{\circ} \mathrm{C}$, the storage modulus fell down the measurement range of the instrument. From around $100^{\circ} \mathrm{C}$ up to $150^{\circ} \mathrm{C}$, the storage modulus increased with increasing temperature. The DSC thermogram exhibited a step transition around the temperature range of the sud-

\section{Uncured Sample}
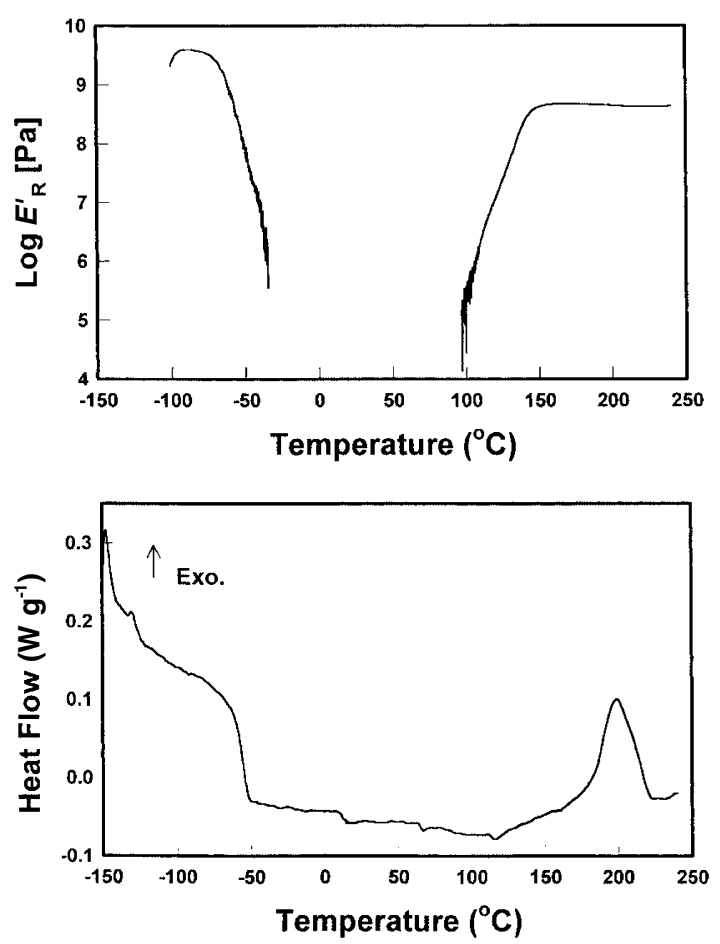

Figure 2. Log relative storage modulus $\left(E_{\mathrm{R}}^{\prime}\right)$ from DMA and heat flow from DSC vs. temperature for the uncured specimen.

den decrease in the $\log E_{\mathrm{R}}^{\prime}$ curve. The glass transition temperature from the inflection point of the DSC step transition was determined to be $-55^{\circ} \mathrm{C}$. An exothermic peak on the DSC curve appeared in the temperature range of around $120^{\circ} \mathrm{C}$ and $220^{\circ} \mathrm{C}$.

Figure 3 exhibits log storage modulus $\left(E^{\prime}\right)$ and $\tan \delta$ from DMA and heat flow from DSC for the light-cured specimen. Interestingly, the $\log E^{\prime} v s$. temperature curve showed two abrupt decreases at low temperature $\left(G_{\mathrm{L}}\right)$ and at high temperature $\left(G_{\mathrm{H}}\right)$. The abrupt decrease in the modulus as a function of temperature is attributed to the glass transition of the material. In the corresponding $\tan \delta v s$. temperature curve, two separate and distinct transitions were observed at the maximum peak temperatures of $55^{\circ} \mathrm{C}\left(P_{\mathrm{L}}\right)$ and $160^{\circ} \mathrm{C}\left(P_{\mathrm{H}}\right)$ due to the two glass transitions. The DSC thermogram in the figure for the light-cured specimen showed an exothermic peak ranging from $45^{\circ} \mathrm{C}$ to $150^{\circ} \mathrm{C}$, but no distinct step transition (i.e., glass transition) was observed.

In order to examine the thermal reaction of the unreacted residual groups, the light-cured specimen was post-cured by scanning to $175^{\circ} \mathrm{C}$ above the DSC exothermic peak in Figure 3. Immediately after the post-cure heat treatment, the specimen was quenched and rescanned and the DMA and DSC results are shown in Figure 4. The dotted curve in the figure is for the light-cured specimen. The glass transition at low temperature $\left(G_{\mathrm{L}}\right)$ in the $\log E^{\prime}$ data for the light-cured spec- 


\section{Light-cured for $40 \mathrm{sec}$}
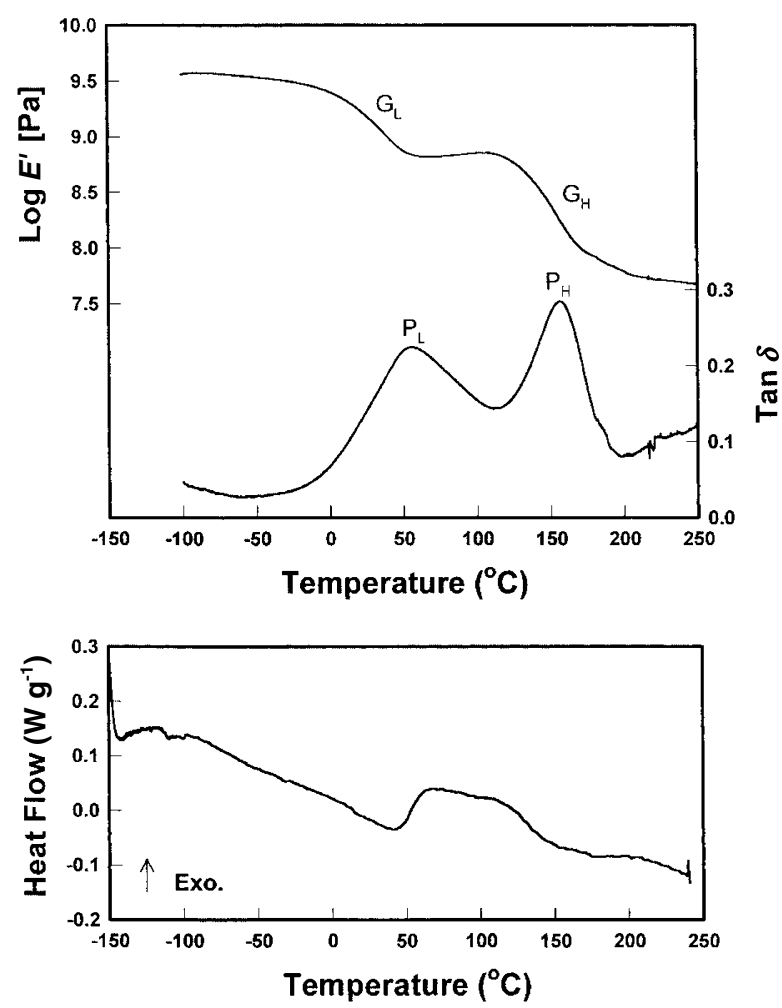

Figure 3. Log storage modulus $\left(E^{\prime}\right)$ and $\tan \delta$ from DMA and heat flow from DSC vs. temperature for the light-cured specimen.

imen shifted to higher temperature and the double decrease of storage modulus became almost a single decrease due to the post-cure heat treatment. Accordingly, the $\tan \delta$ peak at low temperature $\left(P_{\mathrm{L}}\right)$ for the lightcured specimen became much smaller by the post-cure while that at high temperature $\left(P_{\mathrm{H}}\right)$ remained almost the same.

\section{DISCUSSION}

In this study, interesting results were found for the light-cured specimen by the observation of dynamic mechanical properties. An exothermic peak on the DSC curve appeared in the temperature range of around $120^{\circ} \mathrm{C}$ and $220^{\circ} \mathrm{C}$ for an unirradiated sample (see Figure 2). This means that radicals can be produced by thermal energy without irradiation of the light and lead to the exothermic reaction during the post-cure heat treatment. The thermal reaction may be closely related to the increase of the storage modulus in DMA as shown in Figure 2. However, only small amounts of reaction during the temperature scan seem to occur since the specimen at room temperature after the scan was flexible (i.e., rubbery) by the manual observation.

The DSC thermogram in the Figure 3 for the lightcured specimen showed an exothermic peak ranging from 45 to $150^{\circ} \mathrm{C}$, but no distinct step transition (i.e.,
Post-cured by heating to $175^{\circ} \mathrm{C}$
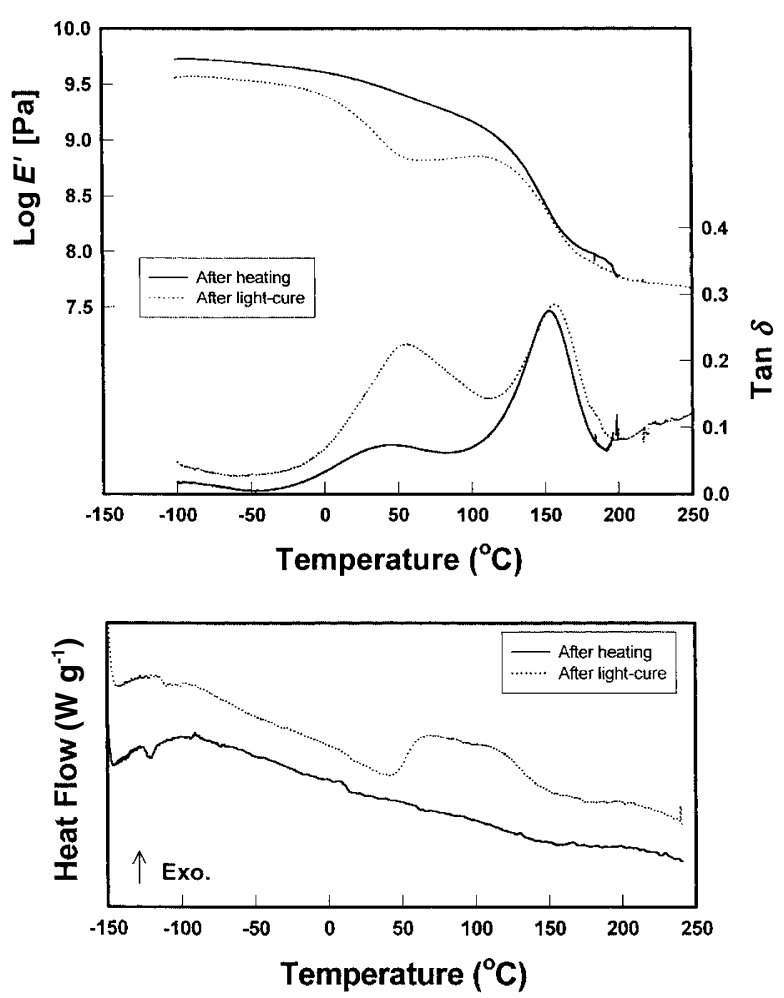

Figure 4. Log storage modulus $\left(E^{\prime}\right)$ and $\tan \delta$ from DMA and heat flow from DSC $v s$. temperature of the light-cured specimen post-cured by heating to $175^{\circ} \mathrm{C}$.

glass transition) was observed. As can be recognized, the dynamic mechanical technique detects molecular relaxations such as those occurring at the glass transition with much higher sensitivity than the DSC although DSC provides quantitative measurements of heat changes such as melting and crystallization. Appearance of the exotherm on the DSC curve indicates that the reaction is not completed by the irradiation $\left(500 \mathrm{~mW} \mathrm{~cm}{ }^{-2} \times 40 \mathrm{~s}\right)$, which usually occurs in normal operative conditions: degree of conversion of commercial dental restorative composites is reported to be 40 $60 \% .{ }^{15-19}$ Note that the exothermic peak on the DSC curve of the light-cured specimen appeared at much lower temperature (i.e., $45-150^{\circ} \mathrm{C}$ ), compared with the uncured specimen (i.e., $120-220^{\circ} \mathrm{C}$ ). This indicates the acceleration of the reaction with lower activation energy through the formation of initiating radicals by irradiation.

From the comparison of the specimens light-cured (dotted curve) and post-cured (solid curve) in Figure 4, the post-cure heat treatment affects greatly on dynamic mechanical and thermal properties. The glass transition at low temperature $\left(G_{\mathrm{L}}\right)$ in $\log E^{\prime}$ data for the lightcured specimen shifted to higher temperature and the double decrease of modulus became almost a single decrease by the post-cure heat treatment. Accordingly, 
Five temperature regions

for incompletely cured resin

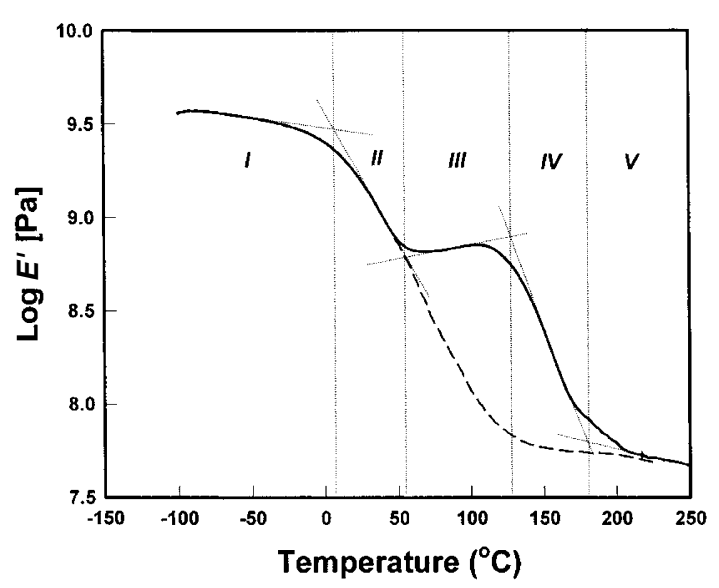

Figure 5. Replot of $\log E^{\prime}$ vs. temperature in Figure 3 showing five different regions (I: glassy, II: glass transition, III: thermal reaction, IV: new glass transition, and V: rubbery).

the $\tan \delta$ peak at low temperature $\left(P_{\mathrm{L}}\right)$ for the lightcured specimen became much smaller by the post-cure heat treatment while that at high temperature $\left(P_{\mathrm{H}}\right)$ remained almost the same. No appreciable exotherm was observed on the DSC curve which indicates near complete degree of conversion after the post-cure heat treatment. Therefore, the further reaction of the unreacted residual group took place during the heating. The glass transition temperature taken from the $\tan \delta$ peak for the post-cured specimen was about $155^{\circ} \mathrm{C}$.

Mechanism of the split in the glass transition is considered to be additional thermal cure in the light-cured specimen, which is responsible for the increase of the modulus between the glass transition region. The additional cure becomes obvious if we examine the log $E^{\prime} v s$. temperature data for a light-cured specimen in Figure 3 which is replotted in Figure 5. As shown in Figure 5, the curve can be divided into five temperature regions obtained by intersecting tangential lines: glassy (I), glass transition (II), thermal reaction (III), new glass transition (IV), and rubbery (V). The onset of the glass transition begins at $7^{\circ} \mathrm{C}$. As the temperature is increased, the $E^{\prime}$ continues to decrease rapidly until it reaches a minimum at $54^{\circ} \mathrm{C}$ with the increased mobility of the macromolecular chains. Further increase in temperature produces a gradual increase in the $E$ which is indicative of additional cure with further chain extension and/or cross-linking reaction by thermal energy. Upon further increase in temperature, the increasing $E$ value begins to decrease rapidly again after reaching a maximum at $126^{\circ} \mathrm{C}$ as the additional cure is completed. Consequently, the decreasing region above $126^{\circ} \mathrm{C}$ up to $178^{\circ} \mathrm{C}$ may be viewed as a combined transition that consists of the glass transition of the light-cured material with the superimposed effect of additional cure. Thus, in effect, a new material has been created which in turn proceeds through its glass transition resulting in the appearance of another transition.

The glass transition temperature can usually be defined in terms of temperature of peak maximum exhibited in the $E^{\prime \prime}$ or $\tan \delta$. As shown in the incompletely cured specimen by irradiation, the glass transition region was disturbed by the thermal reaction. In Figure 5, the dashed curve in $E^{\prime}$ is drawn assuming that there is no thermal reaction in the transition region. If this is the case, one can decide $T_{\mathrm{g}}$ with accuracy from the corresponding $E^{\prime \prime}$ or $\tan \delta$ peak as usual. However, it is certain that the $T_{\mathrm{g}}$ value from the $\tan \delta$ peak at low temperature (i.e., $P_{\mathrm{L}}=55^{\circ} \mathrm{C}$ ) in Figure 3 must be an underestimated of actual $T_{\mathrm{g}}$ of the irradiated specimen. When the additional thermal cure reaction is involved within the step transition on the DSC curve, it will be also difficult to determine the $T_{\mathrm{g}}$ by means of the DSC test.

It is reported that fast reaction in light-curing materials induces incomplete functional group conver$\operatorname{sion}^{15-19}$ and excess amount of free volume in the material. ${ }^{20,21}$ The incomplete functional groups are trapped in the form of residual monomers and unreacted pendent groups by reducing the diffusivity of the reactive species greatly as a result of the rapid gelation and vitrification during the light polymerization. Zhu et $a l^{22}$ and Tial et al. ${ }^{23}$ reported that the lifetime of residual free radical at room temperature could reach several days or months, depending on cross-linking density and storage temperature. Marino et al. ${ }^{24}$ showed that the reaction of an irradiated unsaturated polyester specimen was observed for several days in the dark. When the reaction proceeds rapidly, an excess free volume is also produced since there is no time for molecules to be relaxed in the amorphous state by entering into the vitreous state. The existence of the residual groups for a long period with an excess amount of free volume indicates that further reaction may take place and lead to the changes in properties during heating as well as storing isothermally even at a relatively low temperature (e.g., body temperature).

\section{CONCLUSION}

Incomplete cure and excess free volume in the material is characteristic of a fast reacting system like lightcurable dental resin. In this study, interesting results were found for the irradiated specimen by the observation of dynamic mechanical properties. With the aid of differential scanning calorimetric data, further thermal 
cure reaction with increasing temperature occurs within the glass transition region. There exist two glass transitions due to the thermal reaction: one at low temperature for the light-cured specimen and the other at high temperature for the combined the light-cure and additional thermal reaction. The occurrence of the thermal reaction leads to an inaccuracy in determining $T_{\mathrm{g}}$ and change of properties.

Acknowledgment. This paper is supported by a 2002 Research Fund from Kumoh National Institute of Technology.

\section{REFERENCES}

1. K. P. Menard, "Dynamic Mechanical Analysis: a practical introduction”, CRC Press LLC, Boca Raton, FL, 1999.

2. L.-A. Linden, in "Radiation Curing in Polymer Science and Technology", J. P. Fouassier and J. F. Rabek, Eds., Elsevier Applied Science, London, 1999, p 387.

3. R. L. Clarke, Biomaterials, 10, 549 (1989).

4. J. Vaidyanathan and T. K. Vaidyanathan, J. Mater. Sci., Mater. Med., 6, 670 (1995).

5. D. Buch, D. Wehbi, and C. Roques-Carmes, J. Biomed. Mater. Res., 29, 849 (1995).

6. S. Kalachandra, R. J. Minton, T. Takamata, and D. F. Taylor, J. Mater. Sci., Mater. Med., 6, 218 (1995).

7. K. Saber-Sheikh, R. L. Clarke, and M. Braden, Biomaterials, 20, 817 (1999).

8. R. L. Sakaguchi, N. C. Shah, B. S. Lim, J. L. Ferracane, and
S. E. Borgersen, Dent. Mater, 18, 197 (2002).

9. A. Peutzfeldt, Eur. J. Oral Sci., 105, 97 (1997).

10. J. F. Glenn, in "Biocompatibility of dental materials", D. C. Smith and D. F. Williams, Eds., CRC Press Inc., Boca Raton, FL., 1982 vol III, p 98.

11. E. Asmussen and A. Peutzfeldt, Dent. Mater., 14, 51 (1998).

12. D. J. Indrani, W. D. Cook, F. Televantos, M. J. Tyas, and J. K. Harcourt, Dent. Mater., 11, 201 (1995).

13. N. M. Mohsen, R. G. Craig, and F. E. Fillsko, Can. Assoc. Radiol. J., 49, 224 (1998).

14. R. M. Guerra, I. Duran, and P. Ortiz, J. Oral. Rehabil., 23, 632 (1996).

15. I. E. Ruyter and H. Oysaed, Acta. Odontol. Scand., 40, 179 (1982).

16. G. C. Eliades, G. J. Vougiouklakis, and A. A. Caputo, Dent. Mater., 3, 19 (1987).

17. K. Chung and E. H. Greener, J. Oral. Rehabil., 15, 555 (1988).

18. S. Imazato, J. F. McCabe, H. Tarumi, A. Ehara, and S. Ebisu, Dent. Mater., 17, 178 (2001).

19. J. M. Antonucci and E. E. Toth, J. Dent. Res., 62, 121 (1983).

20. C. N. Bowman and N. A. Peppas, Macromolecules, 24, 1914 (1991).

21. J. G. Kloosterboer, van de G. M. M. M. Hei, R. G. Gossink, and G. C. M. Dortant, Polym. Commun., 25, 322 (1984).

22. S. Zhu, Y. Tian, A. E. Hamielec, and D. R. Eaton, Macromolecules, 23, 1144 (1990).

23. Y. Tian, S. Zhu, A. E. Hamielec, D. B. Fulton, and D. R. Eaton, Polymer, 33, 384 (1992).

24. T. Marino, O. Y. Long, and D. C. Neckers, Ind. Eng. Chem. Res., 34, 4549 (1995). 